Бодяко Анна Владимировна канд. экон. наук, ФГОБУ ВО «Финансовый университет при Правительстве Российской Федерации», г. Москва e-mail: tmguu@mail.ru

\section{Bodyako Anna}

Candidate of Economic Sciences, Financial University under the Government of the Russian Federation, Moscow e-mail:tmguu@mail.ru

\section{ПРОБЛЕМЫ АДАПТАЦИИ РОССИЙСКОЙ УЧЕТНО- КОНТРОЛЬНОЙ И АНАЛИТИЧЕСКОЙ ПРАКТИКИ К ВЫЗОВАМ ЦИФРОВОЙ ЭКОНОМИКИ}

\begin{abstract}
Аннотация. Определены ключевые позиции концептов иүифровой экономики как феноменов осмысления иелей хозяйствования. Рассмотрены причинно-следственные основы проблемы распространения циифровых технологий - одной из характерных особенностей будущего мира, обусловленных прогрессом в областях микроэлектроники, информационных технологий и телекоммуникаций. Сделаны выводы, что теоретические основы проблемы обновления учетно-контрольной и аналитической методологии в ближайтей перспективе и развития понятийного аппарата требуют решения следующих вопросов: повышения степени информационности отчетности; необходимости формирования новых терминов и концепций информационного обеспечения управления финансово-хозяйственной деятельностью.

Ключевые слова: учет, теория управления, циифровая экономика, бухгалтерский учет, отчетность, система бухгалтерского учета.

\section{PROBLEMS OF ADAPTATION OF RUSSIAN ACCOUNTING AND CONTROL AND ANALYTICAL PRACTICES TO THE CHALLENGES OF THE DIGITAL ECONOMY}

\begin{abstract}
The key positions of the concepts of the digital economy as phenomena of understanding the goals of management are defined. The article deals with the cause and effect basis of the problem of digital technologies the spread-one of the characteristic features of the future due to the progress in the microelectronics, information technology and telecommunications. It is concluded that the theoretical basis of the problem of updating the accounting and analytical methodology in the near future and the development of the conceptual apparatus require the solution of the following issues: increasing the degree of information reporting; the need for the formation of new terms, new concepts of information management of financial and economic activities.

Keywords: accounting, control theory, digital economy, accounting, and reporting, accounting system.
\end{abstract}

Развитие цифровой экономики в России инициировано специалистами и партнерами Всемирного Банка с участием представителей органов власти, российских бизнес-структур, институтов гражданского общества и научно-образовательного сообщества. Цель инициативы - сформировать контур «многостороннего партнерства заинтересованных сторон на национальном и региональном уровнях для развития цифровой экономики в России. Главная задача - совместная разработка рекомендаций для заинтересованных сторон по созданию фундаментальных основ развития цифровой экономики в России» [14].

Несмотря на широкое освещение средствами массовой информации и открытой печати способов воплощения такой инициативы в реальную практику, на сегодняшний день в мире не существует единого понимания такого явления, как «цифровая экономика», зато существует множество определений [5]. В указе Президента РФ от 09.05.2017 г. № 203 «О Стратегии развития информационного общества в РФ на 20172030 годы» содержится официальное, так называемое, «государственное определение» данному феномену: «цифровая экономика - хозяйственная деятельность, в которой ключевым фактором производства являются данные в цифровом виде, обработка больших объемов и использование результатов анализа которых по сравнению с традиционными формами хозяйствования позволяют существенно повысить эффективность различных видов производства, технологий, оборудования, хранения, продажи, доставки товаров и услуг» [1]. Заметим, что «данные в цифровом виде» известны задолго до появления феномена «цифровая экономика».

По мнению автора, данное определение является вполне обыденным для официального документа, однако, его приложение к реальным условиям хозяйствования будет существенно затруднено, поскольку неясно, с какими «традиционными формами хозяйствования» надлежит сравнивать «результаты анализа цифрового информационного массива». Наконец, в определении любого термина не следует упоминать о его 
эффективности. Термин сам по себе эффективности не несет, разве только может предполагаться, что его содержание, воплощенное в реальные конструкции (системы, механизмы, инструменты, методы, способы, приемы) могут позитивно воздействовать на результаты хозяйственной деятельности.

Отсутствие четкого определения термина «цифровая экономика» не помешало изданию книги «Введение в «Цифровую» экономику», в предисловии которой отмечена причина ее опубликования: «во время Петербургского международного экономического форума, прошедшего 1-3 июня 2017 г., глава государства еще раз продемонстрировал свой последовательный интерес к цифровой экономике. Начиная с этого момента, в геометрической прогрессии начался рост количества всевозможных мероприятий (конференций, форумов и заседаний) и публикаций на эту тему. <..> Ажиотаж вокруг феномена цифровой экономики, с одной стороны, и отсутствие единого понятийного поля, с другой, приводят к появлению различных несовместимых мнений» [5].

Интерес к феномену цифровой экономики подогревается многочисленными международными симпозиумами, конференциями, лекциями и семинарами. Одним из знаковых событий конца 2017 г. стало проведение целой серии научно-практических конференций по проблемам адаптации учета, контроля анализа, аудита к новым запросам менеджмента. В декабре проведена Международная научнопрактическая конференция «Цифровое будущее инновационной экономики России», организованная кафедрой финансового контроля, анализа и аудита ФБГОУ ВО «Российский экономический университет им. Г. В. Плеханова». Все выступления участников конференции объединял общий вывод о необходимости работы с большими массивами данных, постоянного их обновления и адресная передачи. Поэтому будущее экономики органически увязывается с ускоренным развитием инфраструктурных элементов и основных направлений формирования современной цифровой среды для устойчивого продвижения процесса научной, производственной и социально-культурной деятельности [7].

Многие докладчики, в частности профессоры ФБГОУ ВО «Московского государственного университета имени М. В. Ломоносова» В. Т. Чая и В. П. Суйц, ФБГОУ ВО «Финансового университета при Правительстве РФ» (далее - Финансовый университет) М. В. Мельник, канд. экон. н., доцент Н. Д. Бровкина акцентировали внимание на вопросе о том, как цифровые технологии учета могут повлиять на учетно-контрольные и аналитические процессы. Отмечено, что расширение параметров аудита и дистанционного внутреннего контроля за достоверностью данных через специальные технологии обнаружило потребность более полного выявления связей между отдельными параметрами отчетности [8; 15]. Однако эти ученые не конкретизировали свое видение, каким образом эти связи могут быть установлены. Отсутствие конкретных предложений по методико-цифровому обеспечению учетно-контрольных и аналитических процессов свойственно всем научным конференциям последних трех лет. Это подтверждает как сложность цифровизации этих процессов, так и неготовность российского научного сообщества к решению актуальных вопросов информационноцифрового обслуживания запросов менеджмента экономических субъектов.

Цифровизация подготовки релевантной информации расширяет творческие возможности всех участников этого процесса, не ограничивая их стандартами формирования отчетности по западным образцам. Однако IX научно-практическая конференция, состоявшаяся в Финансовом университете (декабрь 2017 г.), была посвящена стандартизации учета, анализа и аудита как одному из наиболее актуальных аспектов современного этапа совершенствования учетно-контрольных и аналитических методов. В резолюции конференции записано, что в настоящее время особая актуальность стандартизации определяется переходом на цифровую экономику, расширением использования международных стандартов финансовой отчетности (далее - МСФО) и международных стандартов аудита (далее - MCA), а также внутреннего контроля и аудита. В этой связи первоочередной задачей становится стандартизация аналитических процессов, связанная, прежде всего, со стандартизацией системы показателей, однозначностью их экономической интерпретации и методов их аналитической обработки, позволяющих дать всестороннее и четкое обоснование управленческих решений, минимизировать риски потерь и обеспечить устойчивый рост эффективности экономики. Аналогичные требования к учетно-аналитическим и контрольным процессам были предъявлены в период разработки и широкого внедрения в практику автоматизированных систем производства и управления. Поэтому изучение опыта прошлых лет может значительно помочь в решении современных задач, избежать многих ошибок. В этой связи возникают два вопроса, во-первых, о целесообразности стандартизации методов учета, контроля и аналитики, рекомендуемых зарубежными профессиональными сообществами, для принятия управленческих 
решений сообразно специфике российских экономических субъектов. Во-вторых, это вопрос о возвращении к методикам учета, анализа и контроля, используемых в прошлом. Несомненно, это - наследие великих ученых и его следует помнить, возможно, и использовать некоторые принципиальные положения, однако, принимать их как некий эталон - значит не учитывать коренным образом изменившуюся экономическую среду и отношения в ней хозяйствующих субъектов с институциональными регуляторами (Банком России, Министерством финансов РФ (далее - Минфин) и др.).

Опасность для результативного управления финансово-хозяйственной деятельностью экономических субъектов составляет не только применение устаревших методов учета, анализа и контроля, но и насаждение в отечественную аналитическую науку и практику зарубежных концептов. В частности, профессор В. И. Бариленко считает, что коммерческим организациям важно иметь инструмент для выявления проблем, требующих решения, и обоснования мер по созданию условий для своего устойчивого развития, роль которого способен выполнять бизнес-анализ [3]. Весьма сомнительно, что каким бы совершенным не был инструмент информационного сопровождения принятия управленческих решений, он не способен «самостоятельно выявлять проблемы». Проблемной будут, на наш взгляд, практическая реализация рассматриваемой концепции единого интеграционного пространства экономической деятельности, поскольку В. И. Бариленко предполагает реализовать проект по принципу особой экономической зоны, организуемой в цифровом пространстве, не имеющей пространственной локализации. Предполагается строго добровольный порядок присоединения и выхода участников. Пилотный проект может быть реализован в рамках одного или нескольких субъектов Российской Федерации [3, с. 27]. Здесь автор говорит об отсутствии пространственной локализации и сразу же указывает на конкретных участников - присоединяющие добровольно регионы. Если автор подразумевает под своей концепцией создание виртуальной экономической зоны, то российские субъекты власти и бизнеса к такому новшеству организации управления бизнесом не готовы, да, и вряд ли будут готовы в ближайшей перспективе.

О создании единой теории бухгалтерского учета говорят профессоры И. А. Слободняк и Т. Г. Арбатская [12]. Однако в статье не показано, что есть критерий единства, и с чем подразумевается единение.

Дискуссионным представляется, на наш взгляд, утверждение Р. П. Булыги на конференции «Цифровое будущее инновационной экономики России» (декабрь 2017 г.), особое внимание уделившего требованиям, которые предъявляются к учетно-контрольным процессам новыми технологиями, характерными для цифровой экономики, что предполагает ускоренное решение вопроса о совершенствовании стандартизации всех их стадий, реализации сквозного характера учета (финансового, управленческого, налогового), контроля (технико-технологического, качества продукции и работ, производственного, финансового, внутреннего и внешнего) и анализа (Федеральная служба аккредитации на уровне подготовки производства, текущего, последующего, оценочного и т. п.) [4; 15]. Каким образом будет обеспечена реализации сквозного характера учета, анализа и контроля докладчик не сообщил, так как эту задачу предстоит решать дифференцированно на основе специфики экономических субъектов.

Следовательно ощущение неизбежных перемен в информационном обеспечении управленческих решений уже реальность, однако, каким образом это произойдет, докладчики пока предположить не смогли, они только обозначали проблемы.

Как отмечает аудитор Е. Анненкова, с 2018 г. изменился регламент аудита бухгалтерской (финансовой отчетности). В 2017 г. проведение аудита бухгалтерской отчетности осуществлялось в соответствии с федеральными правилами (стандартами) аудиторской деятельности, утвержденными Правительством РФ, и федеральными стандартами аудиторской деятельности, утвержденными Минфином. Эти документы утратили силу с 01.01.2018 г. и при аудите отчетности за 2017 г. применяться не могут, в связи с введением в действие 48 МСА. Кроме МСА, при проведении аудита за 2017 г. применяют и другие документы, принятые Международной федерацией бухгалтеров [2].

Еще дальше по пути инновационных изобретений в сфере учета, анализа и контроля продвинулись профессоры В. С. Плотников, О. В. Плотникова, выдвинувшие гипотезу о замене принципов бухгалтерского учета некими «качественными характеристиками информации Интегрированного отчета» [9]. Эти авторы уверены, что «модели бизнес-учета и интегрированной отчетности ориентированы на отражение результатов процессов создания стоимости во времени при трансформации отдельных видов капиталов организации» [9, с. 7]. 
Трансформационная лихорадка охватила учет, анализ и контроль с выходом на арену финансовохозяйственной и научной деятельности еще одного феномена, представляемого терминами, - «инновации», «инновационная форма развития компаний» $[6 ; 10 ; 13]$.

В статье профессора М. В. Мельника раскрыты основные позиции развития учетно-контрольных и аналитических процессов в организациях с учетом повышения инновационности экономического развития и неустойчивости среды функционирования [8]. При этом, по мнению этого автора, структура информационного обеспечения системы управления взаимосвязана с факторами развития отчетности юридических лиц, как от бухгалтерской к финансовой отчетности, а затем к отчетности в парадигме устойчивого развития и интегрированной отчетности. Здесь не вполне ясно, как структура чего бы то ни было может увязываться с тенденцией развития отчетности, да, и не обозначены критерии разграничения бухгалтерской и финансовой отчетности. Словосочетание «инновационность экономического развития» представляется предметно не определенным. Попробуем понять данные высказывания в контексте и того, что автор расширенно представляет состав «функций управления, включая четкое целеполагание, стратегическое и текущее планирование, внешние коммуникации с партнерами и внутренние связи между подразделениями, учет, анализ, контроль, оценку и мотивацию деятельности отдельных подразделений и предприятия» [8, с. 122].

Подводя итог всему вышесказанному, считаем необходимым отметить несколько существенных аспектов в решении проблемы обновления учетно-контрольной и аналитической методологии в ближайшей перспективе и развития понятийного аппарата.

Во-первых, ставшие модными в последнее десятилетия перехода к так называемому «информационному обществу» термины «гармонизация», «интеграция», «консолидация», «конвергенция» и т. п. побудили представителей ученого сообщества искать варианты повышения степени информационности отчетности. Традиционная бухгалтерская (финансовая) отчетность подверглась критике, и в дополнении к ней стали предлагаться иные виды отчетности с нефинансовой информацией (социальной, экологической, техникотехнологической и др.). Понимание исследователями сложности расширения границ отчетной информации подвигло их к пропаганде «ценностей западных цифровых технологий сбора и обработки информации для отчетности», а также отказу от отечественных стандартов учета, анализа и контроля в угоду зарубежным стандартам. Такая тенденция не может оцениваться положительно, поскольку нереформированными в России остаются сами основы финансово-хозяйственной деятельности, экономика не структурирована: одни отрасли развиваются достаточно интенсивно, а другие остаются на рубеже «каменного» века (строительство, жилищнокоммунальное хозяйство, транспортно-складское хозяйство).

Во-вторых, если и следовать мировым тенденциям развития экономического знания, то необходимо весьма критично относиться и к новым терминам, и к новым концепциям информационного обеспечения управления финансово-хозяйственной деятельностью. Уместно привести предостережение экономистам лауреата нобелевской премии П. Самуэльсона, о том, «в социальных науках нужно особенно остерегаться «тирании слов». Мир весьма сложен и без того, чтобы в него привносились новая путаница и неясности, связанные с тем, что, во-первых, два различных слова по незнанию используются для обозначения одного и того же предмета, и, во-вторых, одно и то же слово применяется к двум совершенно различным явлениям» [11, с. 164].

B-третьих, большинство терминов, которыми оперирует современная наука и практика информационного обеспечения управленческих решений, определены, пусть и недостаточно четко или вызывают полемику у пользователей, в официальных документах, например, в российском и международном вариантах Концептуальных основ развития учета и отчетности. Оставаясь вспомогательным документом, Концептуальные основы используются составителями финансовой отчетности в качестве методического руководства по применению МСФО в отношении тех вопросов учета, которые не освещены еще в текстах конкретных МСФО. Кроме того, Концептуальные основы полезны пользователям финансовой отчетности в их интерпретации показателей финансовой отчетности, составленной в соответствии с МСФО, а также в понимании сути использованных терминов.

В-четвертых, по нашему мнению нет «цифровой экономики» самой по себе. Есть экономика в целом, некоторые сферы которой больше пронизаны автоматизацией, некоторые - меньше. 


\section{Библиографический список}

1. Указ Президента РФ от 09.05.2017 г. № 203 «О Стратегии развития информационного общества в РФ на 2017-2030 годы». Режим доступа: http://www.garant.ru/products/ipo/prime/doc/71570570/ (дата обращения: 15.03.2018).

2. Анненкова, Е. Аудит бухотчетности за 2017 год: что изменилось // [Электронный ресурс]. - Режим доступа: https://buh. ru/articles/documents/65376/ (дата обращения: 12.03.2018).

3. Бариленко, В. И. Бизнес-анализ как инструмент обеспечения устойчивого развития хозяйствующих субъектов // Учет, анализ, аудит. - 2014. - № 1. - С. 25-32.

4. Булыга, Р. П. Классификация и стандартизация финансового контроля и аудита в Российской Федерации. Учет. Анализ. Аудит. - 2017. - № 5. - С. 10-17; № 6. - С. 6-19.

5. Введение в «Цифровую» экономику / А. В. Кешелава, В. Г. Буданов, В. Ю. Румянцев и др.; под общ. ред. А. В. Кешелава; гл. «цифр.» конс. И. А. Зимненко. - ВНИИГеосистем, М.: - 2017. - 28 с. (На пороге «цифрового будущего». Книга первая). Диркова Е. Концептуальные основы МСФО: как их применять? // Информационно-аналитический портал «Предпринимательство и право» [Электронный ресурс]. - Режим доступа: http://lexandbusiness.ru (дата обращения: 15.02.2018).

6. Информация как стратегический ресурс в системе управления бизнесом / С. В. Пономарева, И. В. Лескова, В. В. Зеленов // Российская наука и образование сегодня: проблемы и перспективы. - 2015. - № 3 (6). - С. 101-104.

7. Международная научно-практическая конференция «Цифровое будущее инновационной экономики России» Конференция. Даты проведения: 6 декабря 2017. Место проведения: РЭУ имени Г. В. Плеханова, Россия. - Режим доступа: https://istina.msu.ru/conferences/88967577/ (дата обращения: 12.03.2018).

8. Мельник, М. В. Роль учетно-контрольных и аналитических процессов в развитии системы управления экономических субъектов // Вопросы региональной экономики. - 2016. - № 1 (26). - С. 122-132.

9. Плотников, В. С, Плотникова, О.В.Качественные характеристики информации интегрированной отчетности // Учет. Анализ. Аудит. - 2018. - Т. 5, № 1. - С. 6-17.

10. Рогуленко, Т. М. Информационные цели бухгалтерского учета и отчетности в условиях глобализации экономики / Рогуленко Т. М. // В сборнике: Бухгалтерский учет, анализ и аудит: история, современность и перспективы развития материалы X международной научной конференции студентов, аспирантов, преподавателей. Ответственный редактор Н. А. Каморджанова. - 2015. - С. 24-25.

11. Самуэльсон, П. Экономика: вводный анализ. Т. 1. - М.: Алгон, 1997. - 333 с.

12. Слободняк, И. А. Единая теория бухгалтерского учета как необходимое и достаточное условие формирования единого учетного пространства / И. А. Слободняк, Т. Г. Арбатская // Учет. Анализ. Аудит. - 2015. - № 3. - С. $43-53$.

13. Управление инновационным развитием высокотехнологичных корпораций России: монография / И. В. Никитенко, Т. М. Рогуленко, С. В. Пономарева. - М.: Издательство «Русайнс», 2015. - 200 с.

14. Цифровая экономика (Digital economy). Развитие цифровой экономики в России / Представительство Всемирного банка в России [Электронный ресурс]. - Режим доступа: http://www.vsemirnyjbank.org/ru/events/2016/12/20 (дата обращения: 15.12.2017).

15. IX Международная научно-практическая конференция «Декабрьские чтения памяти С. Б. Барнгольц» на тему «Стандартизация учетно-контрольных и аналитических процессов». (Финансовый университет при Правительстве РФ, 13-14 декабря 2017 г.) [Электронный ресурс]. - Режим доступа: http://www.fa.ru/org/faculty/uia/News/2017-12-12-5.aspx /(дата обращения: 11.03.2018).

\section{References}

1. Ukaz Prezidenta RF ot 9.05.2017 № 203 «O Strategii razvitiya informatsionnogo obshchestva v RF na 2017-2030 gody» [The decree of the President of the Russian Federation from 9.05.2017, № 203 «On the Strategy of information society development in Russia on 2017-2030 years»]. Available at: http://www.garant.ru/products/ipo/prime/doc/71570570/ (accessed 15.03.2018).

2. Annenkova, E. Audit bukhotchetnosti za 2017 god: chto izmenilos' [Accounting Audit for 2017: what has changed]. Available at: https://buh.ru/articles/documents/65376/ (accessed 12.03.2018).

3. Barilenko, V. I. Biznes-analiz kak instrument obespecheniya ustoychivogo razvitiya khozyaystvuyushchikh sub"ektov [Business analysis as a tool to ensure sustainable development of economic entities] // Uchet. Analiz. Audit [Accounting, analysis, audit]. 2014, № 1, pp. 25-32.

4. Bulyga, R. P. Klassifikatsiya i standartizatsiya finansovogo kontrolya i audita v Rossiyskoy Federatsii. [Classification and standardization of financial control and audit in the Russian Federation]. Uchet. Analiz. Audit [Accounting. Analysis. Audit], 2017, № 5, pp. 10-17, № 6, pp. 6-19. 
5. Vvedenie v «Tsifrovuyu» ekonomiku [Introduction to Digital economy] / A. V. Keshelava, V. G. Budanov, V. YU. Rumyancev i dr.; pod obshch. red. A. V. Keshelava; gl. «cifr.» kons. I. A. Zimnenko. Vniigeosystem, Moscow: 2017. 28 p. (Na poroge «tsifrovogo budushchego». Kniga pervaya [On the threshold of the «digital future». Book the first]). Dikova E. Kontseptual'nye osnovy MSFO: kak ikh primenyat'? [Conceptual framework IFRS: how to use them?] // Informatsionno-analiticheskiy portal «Predprinimatel'stvo i pravo» [Information and analytical portal «Entrepreneurship and law»]. Available at: http://lexandbusiness.ru / (accessed 15.02.2018).

6. Informatsiya kak strategicheskiy resurs $\mathrm{v}$ sisteme upravleniya biznesom [Information as a strategic resource in the business management system] / S. V. Ponomareva, I. V. Leskova, V. V. Zelenov // Rossiyskaya nauka i obrazovanie segodnya: problemy i perspektivy [Russian science and education today: problems and prospects], 2015, № 3 (6), pp. 101-104.

7. Mezhdunarodnaya nauchno-prakticheskaya konferentsiya «Tsifrovoe budushchee innovatsionnoy ekonomiki Rossii» Konferentsiya. Daty provedeniya: 6 dekabrya 2017. Mesto provedeniya: REU imeni G.V. Plekhanova, Rossiya. [International scientific and practical conference «Digital future of innovative economy of Russia». Dates: December 6, 2017. Venue: Plekhanov Russian University of Economics, Russia]. - Available at: https://istina.msu.ru/conferences/88967577 / (accessed 12.03.2018).

8. Malnik, M. V. Rol' uchetno-kontrol'nykh i analiticheskikh protsessov v razvitii sistemy upravleniya ekonomicheskikh sub"ektov [The role of accounting, control and analytical processes in the development of the management system of economic entities] // Voprosy regional'noy ekonomiki [Regional economy]. 2016. - № 1 (26). - pp. 122-132.

9. Plotnikov, V. S, Plotnikova, O. V. Kachestvennye kharakteristiki informatsii integrirovannoy otchetnosti [Qualitative characteristics of information integrated reporting] // Uchet. Analiz. Audit [Accounting. Analysis. Audit], 2018, Vol. 5, I. 1, pp. 6-17.

10. Informatsionnye tseli bukhgalterskogo ucheta i otchetnosti v usloviyakh globalizatsii ekonomiki [Information purposes of accounting and reporting in the context of globalization of the economy] / Rogulenko T. M. // V sbornike: Bukhgalterskiy uchet, analiz i audit: istoriya, sovremennost' i perspektivy razvitiya materialy X mezhdunarodnoy nauchnoy konferentsii studentov, aspirantov, prepodavateley. [In the collection: Accounting, analysis and audit: history, modernity and prospects of development materials Xinternational scientific conference of students, postgraduates, teachers]. Otv. red. [Resp. editor]: N. A. Kamordzhanova, 2015, pp. 24-25.

11. Samuelson, P. Ekonomika: vvodnyy analiz [Economics: an introductory analysis]. Vol.1. Moscow: Algon, 1997. 333 p.

12. Slobodnyak, I. A. Edinaya teoriya bukhgalterskogo ucheta kak neobkhodimoe i dostatochnoe uslovie formirovaniya edinogo uchetnogo prostranstva [Unified theory of accounting as a necessary and sufficient condition for the formation of a single accounting space] / I. A. Slobodnyak, T. G. Arbatskaya // Uchet. Analiz. Audit [Accounting. Analysis. Audit], 2015, № 3, pp. 43-53.

13. Upravlenie innovatsionnym razvitiem vysokotekhnologichnykh korporatsiy Rossii: monografiya [Management of innovative development of high-tech corporations in Russia: monograph] / I. V. Nikitenko, T. M. Rogulenko, S. V. Ponomareva. M.: Publishing House «Rusyns», 2015. 200 p.

14. Tsifrovaya ekonomika [Digital economy]. Razvitie tsifrovoy ekonomiki v Rossii [Digital economy development in Russia] / Predstavitel'stvo Vsemirnogo banka v Rossii. [World Bank Representative office in Russia]. Available at: http://www.vsemirnyjbank.org/ru/events/2016/12/20/ (accessed 12.03.2018).

15. IX Mezhdunarodnaya nauchno-prakticheskaya konferentsiya «Dekabr'skie chteniya pamyati S.B. Barngol'ts» na temu «Standartizatsiya uchetno-kontrol'nykh i analiticheskikh protsessov». (Finansovyy universitet pri Pravitel'stve RF, 13-14 dekabrya 2017) [IX international scientific and practical conference «December readings in Memory of SB Barngolts «on» Standardization of accounting and control and analytical processes». (Financial University under the government of the Russian Federation, December 13-14, 2017)]. Available at: http://www.fa.ru/org/faculty/uia/News/2017-12-12-5.aspx / (accessed 11.03.2018). 